\title{
The Online Eunuch as a 'CyborgianTrans' \\ Figuration: \\ De-stabilising Gendered \\ Meanings and \\ Subjectivities
}

Surinderpal Kaur

Universiti Malaya, Malaysia

SARE: Southeast Asian Review of English, Vol. 54, Issue 1, 2017 


\title{
SARE, Vol. 54, Issue 1| 2017
}

\begin{abstract}
Like the materially bounded body, the representation and reproduction of the online body is subject to ambiguities and multiplicities. Online discussion boards provide spaces that not only reinforce traditional norms and practices related to gender and sexuality but also provide spaces that highlight the transgressions of these traditional norms and practices. This paper aims to explore the ways in which the category of 'eunuch' is reimagined in multiple subjectivities in online interactions, specifically by examining how the body of a eunuch is constituted in online discussion boards. Importantly, the paper also proposes the analytical construct of the "CyborgianTrans" in order to reveal the multiplicities and ambiguities inherent in online self-representations of eunuch identities.
\end{abstract}

Keywords: gender, sexuality, online identity, eunuch

This paper focuses upon gender ambiguity in online representations of the eunuch self, examining the ways in which the material offline body, specifically the body of a eunuch, could be reproduced or represented in online spaces. The paper focuses upon the myriad of ways in which the term eunuch itself is represented and presented in the online world - ways which work to de-stabilise the very term eunuch itself and the current and historical meanings ascribed to it. In order to explore how the discursive performativity of gender in online discussion boards works in many different and scrambled ways to produce multiple subjectivities as well as multiple definitions of the 'eunuch', I propose the construct of the 'CyborgianTrans' as an analytical resource.

The materially-bounded body is disembodied in cyberspace; participants have to rely upon images, i.e. avatars, to map their material body onto cyberspace, in the process opening up experiences of multiple configurations of sex and gender. Thus, virtual spaces have the potential to reframe the relationship between 'original meanings ascribed to gender' and the 'subsequent gender experience' as the relationship between the materially-bounded body and, what Judith Butler refers to as, an "internal locale of gender identity" (171) cannot be taken for granted. In postmodern terms, the norms of gender exist in a hyperreal world where there is no reality but, rather, a simulacrum of femininity and masculinity that is mapped upon the physical body (in terms of ideal appearance, behaviour and desire). If we transpose this idea of gender as a simulacrum onto another space where simulacra abound - cyberspace - we find that the whole notion of an internally fixed gender becomes even more suspect. In online environments, such as those exemplified by role-playing games like World of Warcraft, where behaviour, self-presentation and actions involve simulations of originals that do not actually exist, gender is represented through textual and visual means that preclude material bodies. The simulacrum of gender becomes intertwined with other simulacra, opening spaces for transgressions of the purported 'reality' of gender.

In order to develop a framework that would focus upon gender, biological sex and sexual desire in terms of multiplicities, crossings and affinities, as well as to show how gender categories are presented, maintained and troubled online by different subjectivities, I propose the analytical construct of the 'CyborgianTrans', which draws heavily from the postmodernist feminist thoughts of Donna Haraway. Haraway's work is also particularly apt in this case as there is the added dimension of the role that technology plays in the creation of online spaces and subjectivities. 


\section{SARE, Vol. 54, Issue 1 | 2017}

\section{The notion of the 'Cyborg'}

Haraway's famous proclamation "I would rather be a cyborg than a goddess" (181) in her seminal work, The Cyborg Manifesto, highlights the significance of transcending fixed gender boundaries and creating new empowering possibilities for women (I would argue here other gendered subjectivities as well) in the process. The figure of the cyborg is a hybrid combination of an organic being (both human and animal) and a machine, blurring defined boundaries between organisms and machines. It is a metaphor for a figure that refuses to be located within one particular category, preferring to lie instead in the so-called 'natural' boundaries between categories such as those between sex/gender; body/mind; nature/culture. The key feature of the cyborg is a suspicion of anything that is 'natural', and a delight in the possibilities of creating new and 'unnatural' (possibly even anarchic) affiliations afforded by technology.

While the word 'cyborg' may conjure up fantastical images of technological monsters, cyborgs are actually far more commonplace. We have individuals whose bodies are reconfigured technologically with electronic pacemakers or corneal lenses, or even artificial limbs. We also have individuals whose bodies remain biologically intact, but whose social realities are mediated through technology, such as playing video games on the Xbox, or the Playstation, using Satellite-Navigation systems or even individuals who use hardware such as computers, monitors and keyboards, and software such as word processors or spreadsheets to do their daily work. The human body is cyborgian in its integration with everyday scientific and technological advances that allow the body to transcend its so-called 'nature' as a bounded entity.

In this world of scientific and technological advances, the cyborg imagery shows the permeability of boundaries. Echoing Haraway's argument that since "communications technologies and biotechnologies are the crucial tools recrafting our bodies" (164), these are also tools by which the cyborg reconfigures itself as well as the hierarchical oppositions it is surrounded by.

When it comes to binary oppositions, the figure of the cyborg does not rely upon finding unity through the logic of "appropriation, incorporation, and taxonomic oppositions" (42). As a boundary figure, the cyborg rejects the binary position of either/or, and takes up the position of both oppositions or neither oppositions, in the process disrupting the hegemonies that legitimise these so-called 'natural' boundaries in the first place. When it comes to opposing categories such as self and other, the cyborg takes great delight in not locating itself in one or the other. Society marks certain individuals (such as women) as the 'other' in opposition to their 'self'. The figure of the cyborg does not seize the tools of the dominators to reject this interpellation of itself as the other, or appropriate the 'self' subject position. Rather the cyborg seizes the tools in order to "mark the world that marked them as other" (175), and in the process, creates confusion about the boundaries that have hitherto been seen as 'fixed' and 'natural'. Just as significantly, the cyborg takes great 'pleasure in the confusion of boundaries' (150).

The cyborg embodies the indeterminacy of bodies as fixed entities in discourse. Because the cyborg occupies a subject position which is both, this and that, or, neither this nor that, or even both (rather than this or that), it is a creature that cannot be employed in the legitimation of gender stereotypes, or in the fixing of gender within narrow and coherent terms of identity. Thus, from a feminist point of view, a cyborg is a subject position based in affinities across boundaries. 'Woman' seen through the lens of binary oppositions is either 'whore' or 'virgin'; the cyborg however, is both whore and virgin at the same time, and yet it is also neither (Haraway, 1991). 


\section{SARE, Vol. 54, Issue 1 | 2017}

Like Judith Butler, Haraway's premise is that 'nature' and 'truth' are constructed and that the relationship between biological sex and gender needs redefining. Whilst Butler does this through theorising about alternative performatives such as drag, Haraway suggests that instabilities in gender boundaries can occur through the use of new technologies such as virtual spaces, and through the breakdowns of boundaries between not only organism and machines, as well as well natural and artificial, but also the physical and the non-physical. Haraway argues that the cyborg's main technology for subversion is writing (especially stories and narratives) - it is through writing that the cyborg brings about subversive changes. Stories, then, are told and retold in versions that "reverse and displace the hierarchical dualisms of naturalised identities" (175).

Of course, Haraway's notion of the cyborg is not without its attendant problems. As a political resource, it is unstable and open to contestations (see Sheryl Hamilton's The Cyborg 11 Years Later). The cyborg does not actually make other concepts obsolete, nor is it unique as a concept in itself. Other concepts, such as alterity or displacement, have put forward similar oppositional and radical arguments before. However, I would argue that the complexities, multiplicities and diversities of hybrid forms involving technology that the cyborg embodies is a valuable resource for examining online interactions.

In borrowing from Haraway then, my proposed figuration of the cyborg is an emblem for alternative subjectivities, as well as the creation of new multivocal forms of gendered subjectivities that contest traditional notions of gender. The cyborg figuration stands for the potential for employing technology in disrupting and reconfiguring the conventional and normative boundaries of gender, creating possibilities for alternative subjectivities.

\section{The notion of 'Trans'}

I use the term 'trans' in the broad sense of crossing gender boundaries, in terms of gendered appearance, behaviours, self-presentation and identity. While 'trans' can be used in various configurations, in this paper, the focus upon the term is in relation to occupying the spaces in-between and also, in terms of cutting across boundaries.

The first way in which I employ 'trans' is in terms of occupying the 'in-between' spaces of neatly organised models of sex/gender, i.e. trans/gender. If the cyborg occupies the space on the boundaries, trans is a position that occupies the 'in-between', i.e., the nebulous and ambiguous spaces between the boundaries. Like the cyborg, the figure of the trans also works to disrupt the binary models in sex, gender and desire. In many cases, this particular trans figure is sometimes invisible and marginalised as in the case of transgendered, transsexual or gender dysphoric individuals. However, this does not rule out any notion of agency or empowerment where the figure of the trans is concerned. Because of the non-normative spaces that they occupy, trans figures disrupt normative categories of gender, sex and desire while at the same time, offering different, alternative, multiple and subjective ways for their sexed bodies (material or immaterial) to signify gender.

The second use of trans, in terms of cutting across boundaries and categories, draws from Nira YuvalDavis' notion of transversalism. Foucault refers to "a grid of intelligibility of the social order" (93) where social actors are constituted within specific normative subjectivities that include gender categories. Tranversality cuts across the lines of these normative subjectivities. 


\section{SARE, Vol. 54, Issue $1 \mid 2017$}

Virtual space is a transversal space where intersectionality and multiplicity abound in terms of the potential for reconfiguration of gender categories (through manipulation of visual markers of online gender, and through gender-swapping), but, at the same time, it also produces spaces for rupture and critique of rigid boundaries.

\section{The 'CyborgianTrans'}

The presentation and reproduction of the offline self in an online environment can be perceived as the figure of the Cyborg (in terms of being a hybrid creature) and the Trans (in terms of inhabiting the spaces between normative gender boundaries).

The 'CyborgianTrans' then is a hybrid figure that combines the premises of the cyborg and the trans. It exists in both online and offline environments simultaneously and it both occupies and crosses various boundaries. The CyborgianTrans occupies the in-between spaces between the physical and non-physical, the online and offline, the established normative and non-normative sex/gender/desire categories, and moves (sometimes fluidly, sometimes problematically) between these spaces. It works towards problematising the notion of gender that seeks to fix individuals in 'permanent' and normative categories of gender, sex and sexuality, and in the process, exposes the illusoriness of these gender categories themselves. The CyborgianTrans cannot define itself as outside any subjectivities, whether normative or alternative. The CyborgianTrans may resist normative hegemonies and position itself against the grain of dominant representations, but on the other hand it is just as capable of enacting these normative hegemonic acts.

Sherry Turkle, in her book, The Second Self, argues that the interface between computers and users can enable a space for the extension of the self, creating a second self for people. The CyborgianTrans offers a metaphor by which hopes and promises of offline gendered subjectivities and selves are actively transposed (by members of the boards) to the online environment, in the process reproducing, redefining and re-presenting these subjectivities in a myriad of different and partial ways. I would argue that the CyborgianTrans figuration also allows for an examination of the second self, the self that is the online extension of the offline self. In terms of the figure of the eunuch, the CyborgianTrans figure brings up the possibilities of multiple selves the offline self in relation to a more idealised online self.

David Gunkel highlights the perceived dichotomy between the "real world" and online interaction, which is often seen as an "apparitional other" (135). In this case, the offline self may or may not be castrated or penectomised; it may or may not embody the literal figure of the eunuch. The online eunuch self, as an extension of the offline self, is a more idealised version of the self (and quite possibly also an extension of the internalised Other in the offline self). Gunkel goes to argue that examinations of the 'virtual' are often underpinned by the 'real' (the offline world and self). However, the 'real' (in this case the offline material body) is open to differing interpretations and negotiations (139). Thus, if the 'real' itself is open to interpretation, then the virtual cannot be delegitimised as the 'other'. What the virtual does is call into question the perceived fixedness of the 'real', which is in fact, subject to contestations.

The CyborgianTrans figure highlights the second self here, the online self that the participants of the message boards wish to show other participants. It is the self as they wish to be seen. The online eunuch self may be a 'virtual' self. Yet the 'real' eunuch itself, as a term, is open to contestation and negotiation. I would argue that for the CyborgianTrans figure, both the actual offline self, and ideal online self are multiple ways 


\section{SARE, Vol. 54, Issue 1 | 2017}

of articulating (in both the figurative and the literal sense) the gendered and sexual body of the eunuch, and in the process, de-stabilising the term 'eunuch' and its normative definitions.

\section{The Eunuch in History and Culture}

According to the Merriam-Webster Dictionary, a eunuch is a human male who has been castrated or deprived of his testes. Historically, eunuchs were men who were castrated in order to perform specific court and social functions such as serving as guards and domestic servants in women's quarters (such as harems) as well as courtiers and chamberlains in palaces in the Middle East and China. These eunuchs, castrated either involuntarily or by force, were prized for their association with impotence and the inability to sire children (and thus being threats to the court), often becoming trusted advisors to kings and holding high administrative positions in the court. The castrati, young boys castrated before puberty, were also valued for their high-pitched voices, often singing in the church and in choirs.

While eunuchs in the courts of pre-Mughal Muslim rulers in the Indian sub-continent did enjoy a high level of regard, in the contemporary Indian socio-cultural milieu, hijras are looked down upon. The hijras in India, a loose term denoting male to female transsexuals, do not have access to proper sex reassignment surgery or hormone therapy. Thus, with no other recourse but to have surgical castration, most hijras in India are perceived as eunuchs. Culturally and socially, in India and many parts of the contemporary world, the word eunuch is a somewhat loaded term, associated with being impotent, devoid of desires and the need for sex, as well as deprived of virility, marking an absence of biological, cultural and social codes which mark masculinity and sexuality.

In today's world, there is a perception that becoming a eunuch is matter of choice unlike the eunuchs of history. It is pertinent to point out that some patients with advanced prostate cancer also undergo involuntary castration. Some of them may embrace the term eunuch, while others may not identify with the term at all. Also, medical conditions such as gender dysphoria as well as body integrity identity disorders do affect some individuals' desire for genital ablation. Vale, Siemens et al. argue that undergoing childhood abuse, strong parental religiosity, or having participated in animal castration were all significant factors in the extreme castration ideations of some individuals (230). What is significant is that in today's world, the term 'eunuch' is often couched as a bodily limitation or a medical disorder. I would argue, that the term 'eunuch' cannot be fixed in meaning (whether socially, culturally, historically, politically and medically), and is open to diverse and ambiguous meanings.

\section{Online Eunuchs as CyborgianTrans Figures}

The data is collected (with consent) from the Eunuch Archives Message Board (henceforth Eunuch Archives). Eunuch Archives is an online community of individuals who have a strong interest in castration and penectomy (castration refers to the removal of the testicles while penectomy involves a partial or complete removal of the penis). The name Eunuch Archives itself denotes an umbrella term that leaves itself open to various interpretations of the word 'eunuch', nor necessarily fixed by the historical or cultural definitions of the term.

Some members of this online community have undergone voluntary castration or penectomies but there is also a large number who have neither undergone castration nor been penectomised; Roberts et al. argue that these individuals however, have extreme castration ideations that affect their daily offline lives (1670) and 


\section{SARE, Vol. 54, Issue 1 | 2017}

they strongly wish to voluntarily undergo the procedures if possible, even though they do not have legal, financial or medical recourse to such procedures. A study by Vale, Johnson et al. has shown that many members of the online community do not necessarily have Male-to-Female Gender Dysphoria, and in fact do not intend to present as a female at all (40).

As members of this discussion board often share their own experiences of, or hopes for emasculation, the research site allows me to explore gender and sexual subjectivities that are produced by members of the board who are either eunuchs or intending to become eunuchs. The interface of online discussion boards such as the Eunuch Archives enables users to create digital identities for themselves. While some may argue that the digital self is an extension of the offline materially bounded self, I argue that the digital self is another form of constituted identity. The 'self' in online discussion boards such as the Eunuch Archives is deliberately and consciously created by users who manipulate the virtual environment to produce different ways to create an online self that not only allows others to interact with them, but also enables them to express the 'ideal' self they have envisioned for their bodies (which may not be the bodies they have in the offline world).

The online expression of extreme castration ideations which are not necessarily possible in the material offline world for these individuals are explored as CyborgianTrans figurations through an examination of avatars, signatures, personal profiles and messages, the alternative and plural reproductions of the eunuch selves of four members of Eunuch Archives. I argue that the messages posted by users are, in effect, messages written by CyborgianTrans figures. In the Eunuch Archives community, the online reproduction of the offline self that is, or wants to be, a eunuch, transcends mere representation, and reproduces offline desires and identity markers online while simultaneously reinventing them in different ways.

In the sections that follow, my analysis focuses upon the online self-reproduction of these users through two main areas:

$>$ markers of identity in messages, such as avatars, signatures and nicknames

$>$ markers of gender subjectivity in the public profiles of the users, specifically them

- 'birth gender'

- 'identity gender'

- 'sexual orientation'

- 'desires'

It is significant to note that the public profile pages in Eunuch Archives indicate gender/sex through a series of categories that do not really adhere to normative gender/sex identification markers. For instance, 'birth gender', is used in place of biological sex/gender identification, while a category indicating 'identity gender' is also included alongside sexual orientation. These two categories seem to indicate dichotomous perspectives on what sex/gender a social actor is 'born' as and her or his subsequent experience of gender.

It could be argued that the performativity of gender is most visible in the oft used term 'gender identity', which Scott-Dixon calls the "most innate layer of gender, the core that provides us with a deep sense of who we are" (18). 'Female' and 'male' are essential gender identity terms that are often associated with identity markers based primarily upon bodily criteria such as sex organs. These terms naturalise gender identity into binary categories that are foreclosed by birth and biological sex. By rearranging the structure of the term 'gender identity' into 'identity gender', the Eunuch Archives board offers its members (who are themselves positioned to trouble normative gender categories) a way to resignify the term. Instead of gender being a 'natural', pre-ordained and self-evident identity category in which individuals practise very little agency, the term could offer spaces for alternative thinking whereby social actors can actively acknowledge ambivalent 


\section{SARE, Vol. 54, Issue 1 | 2017}

subjectivities that they experience in their purportedly innate 'identity'. In this way, the organisation of online self-reproduction in the public profile pages for Eunuch Archives seems to mark a clear distinction between what Butler calls the "original meanings ascribed to gender" and "subsequent gender experience" (171).

In the next few sections, I illustrate the gender subjectivities offered by four members of the Eunuch Archives community - Bobbie, Losethem, joydivision27 and Kangan. I argue that these four posters are CyborgianTrans figures who present four alternative and different discursive versions of what it is to be (or want to be) a eunuch (as opposed to what is generally perceived as a eunuch), and in the process, de-stabilise any fixed or exclusive constructions of 'eunuch'.

\section{Bobbie}

Figure A shows a post by Bobbie, a member of the Eunuch Archives. Almost every aspect of the presentation of Bobbie's online self throws up ambiguities and problematises normative gender identity markers.

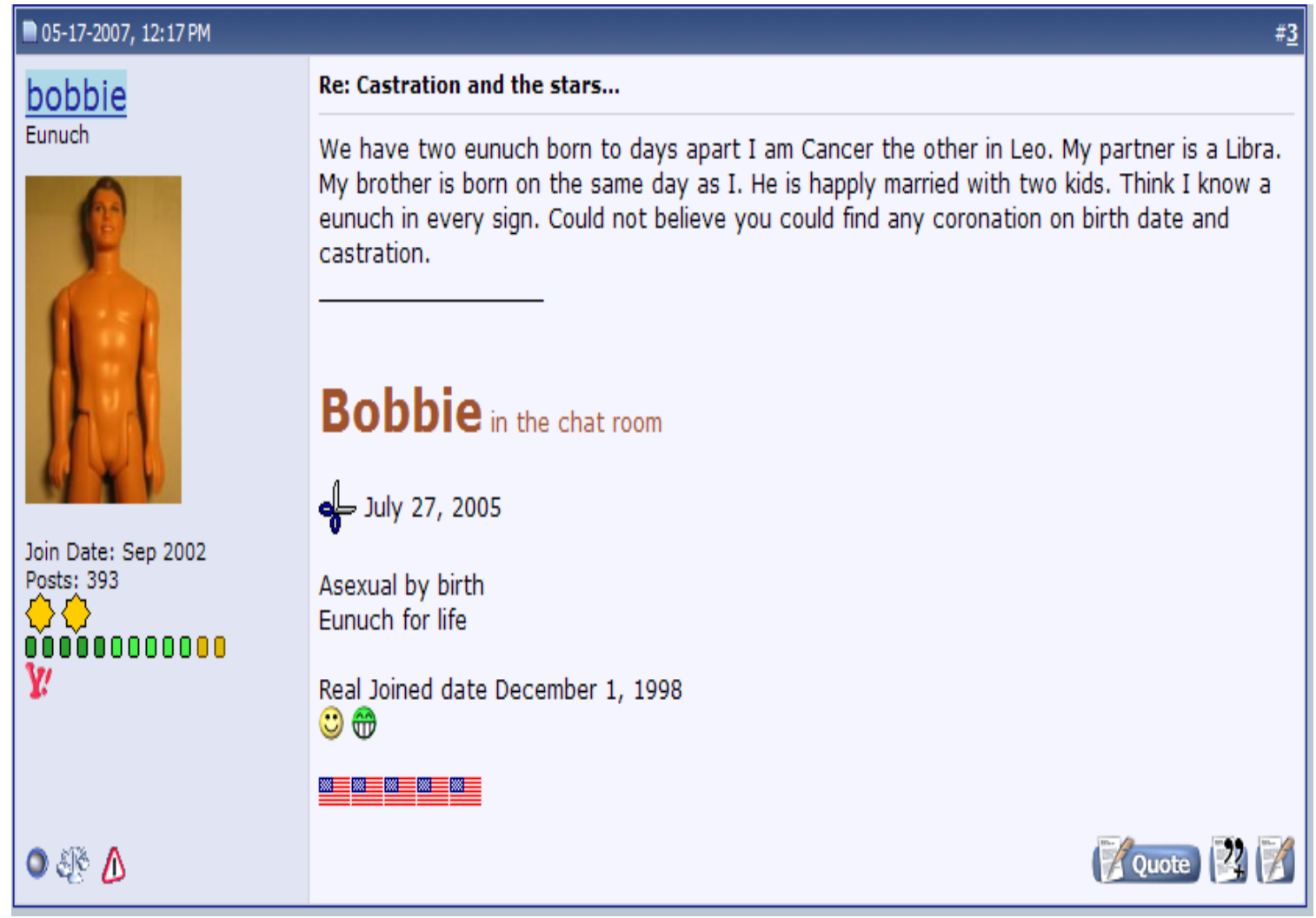

Figure A: Screen capture of Bobbie's post

The name Bobbie itself is somewhat ambiguous as the spelling of this name reflects the feminine version of the name Bobby. Bobbie's arguably feminine name, however, is followed by the word 'Eunuch', while his signature indicates that not only is he a eunuch, but that he is also asexual (see also figure $\mathrm{C}$ ). 


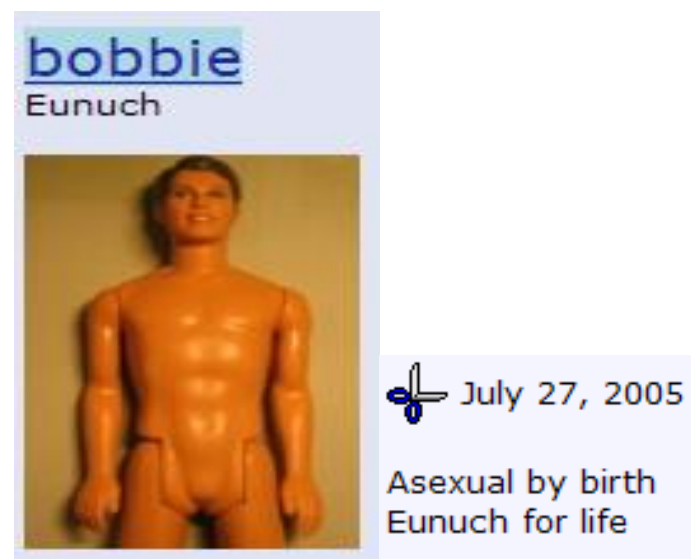

Avatar Signature

Figure B: Close ups of Bobbie's avatar and signature

In the offline world, Bobbie claims that his physical body underwent castration in July 2005 (the scissors icon and the date in the signature indicate this as does his public profile (see Figure $C$ ). At the time of this post on 17 May 2007, Bobbie has been living as a eunuch in the physical world for almost two years (that is if we accept at face value, his claim that he became a eunuch in 2005). Although, he claims his birth gender is 'genetic male', his identity gender is 'asexual eunuch'. The CyborgianTrans figure of Bobbie lives in the spaces 'in-between' the performativity of sexualised masculinity, whether normative (heterosexual) or what Butler would consider non-normative (homosexual). Bobbie rejects any interpellation of himself as a sexual being with a body inscribed with sexual markers. At the same time, he also disrupts any possibility of normative identification with sex/gender/desire categories (whether heterosexual male or homosexual male). 'Asexual eunuch' is placed as an alternative category of identification that rejects cultural fictions of the body as bound by sexual desire and sexual desirability that define the normativity of heterosexuality and homosexuality.

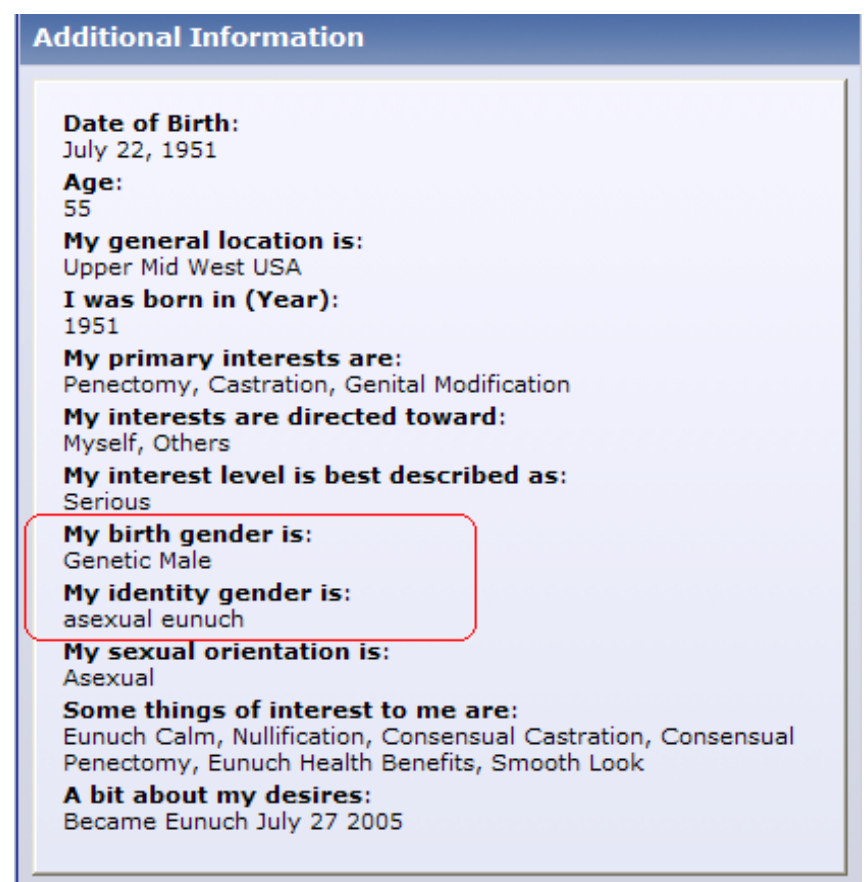

Figure C: Bobbie's public profile 


\section{SARE, Vol. 54, Issue $1 \mid 2017$}

As a CyborgianTrans figure, Bobbie reproduces his offline eunuch self in the online environment, occupying the boundary between physical and non-physical. Bobbie's avatar reinvents his physically-castrated offline self in an online image. The close up of his avatar (Figure B) shows a plastic toy figure of a male with movable limbs and torso, quite possibly a prototype version of the Ken, the companion doll to Barbie. The interesting thing about this image is that although the figure is naked and has a well-defined body, its genitals are not discernible, and are even somewhat ambiguous, pointing towards, Bobbie's own offline asexual, eunuch self.

Bobbie's online representation of his offline body then does not just reproduce the ambiguity of his physical body. Bobbie's online representation could be read to show that Bobbie manipulates the deliberate asexuality of the doll's genitalia (presumably made asexual to 'protect' children). The deliberate use of the male doll image with no discernible genitals, subverts the masculine (yet ironically asexual) image of the toy, and reinvents it in the gender ambiguous figure of the eunuch, at the same time reproducing his own asexuality. It is significant that just as parts of Bobbie's offline physical body have been manipulated, resculpted and eventually transformed through surgical technology, the parts that make up Bobbie's online 'self' are also manipulated and inscribed with markers of his alternative subjectivity, allowing him to 'perform' his 'eunuchness' online.

Of course, Bobbie's choice of avatar could be interpreted along a different point of view. In his profile, he indicates that among some of his interests are, 'consensual penectomy' (the removal of all or parts of the penis) and a 'smooth look'. This could be read to mean that Bobbie's elimination of his physical body parts and the choice of the avatar, could also be a matter of aesthetics, where the clean lines of the 'smooth look' are far more attractive than parts of the body which bulge (more so when aroused).

It would seem to a certain extent that it is a strong possibility that either or both asexuality and aesthetics play a major role in the reproduction of Bobbie's online persona. Which is of more significance to Bobbie? As an analyst, I could make a judgement that it is asexuality based on the frequent references to it in his online messages and his profile. However, I cannot state definitely that it is the case as I am well aware that I am imposing my own interpretations upon his words and messages which could have been produced to intend another meaning altogether.

\section{Losethem}

In this example, I analyse a member named Losethem, whose reproductions of the online self, as well as online writing, are predicated by playfulness and humour. The name Losethem is fairly explicit - it combines the words 'lose' and 'them' in a reference to getting rid of his testicles, in his desire to be a eunuch. Losethem's humour is evident in his selection of image for his avatar (figure D): 


\section{SARE, Vol. 54, Issue 1| 2017}

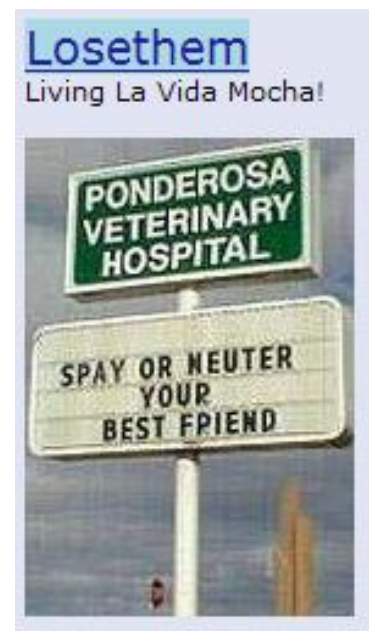

Figure D: Close up of Losethem's avatar

In this avatar, I interpret a deliberate play on the words in the sign "Spay or Neuter Your Best Friend". The context of the image makes it clear that the sign is about neutering pets (especially dogs). Losethem's appropriation of this image in his online self-reproduction, could be read in different ways. In a literal level, he could be seen to be referring to neutering his pet. On another level, the context in which this avatar has been selected and displayed, i.e., the eunuch discussion board, the image could involve several semiotic meanings in terms of connotative meanings. In the first, he recommends spaying or neutering to his best friends (the human variety). In this sense, spaying is seen as a 'kindness' or a positive act which he recommends to others. Another connotative reading could be that the meaning of the sign has been reinvented to refer to neutering his own best friend, which could refer to his penis and testicles. Thus, the CyborgianTrans figure is not just a figure that inhabits the 'in-between' spaces, but is also a playful figure that takes pleasure in being perverse and confusing boundaries. This playfulness extends also to the tools of CyborgianTrans-writing. In writing about his own subjectivity, for example, the CyborgianTrans is just as playful, as Figure E illustrates:

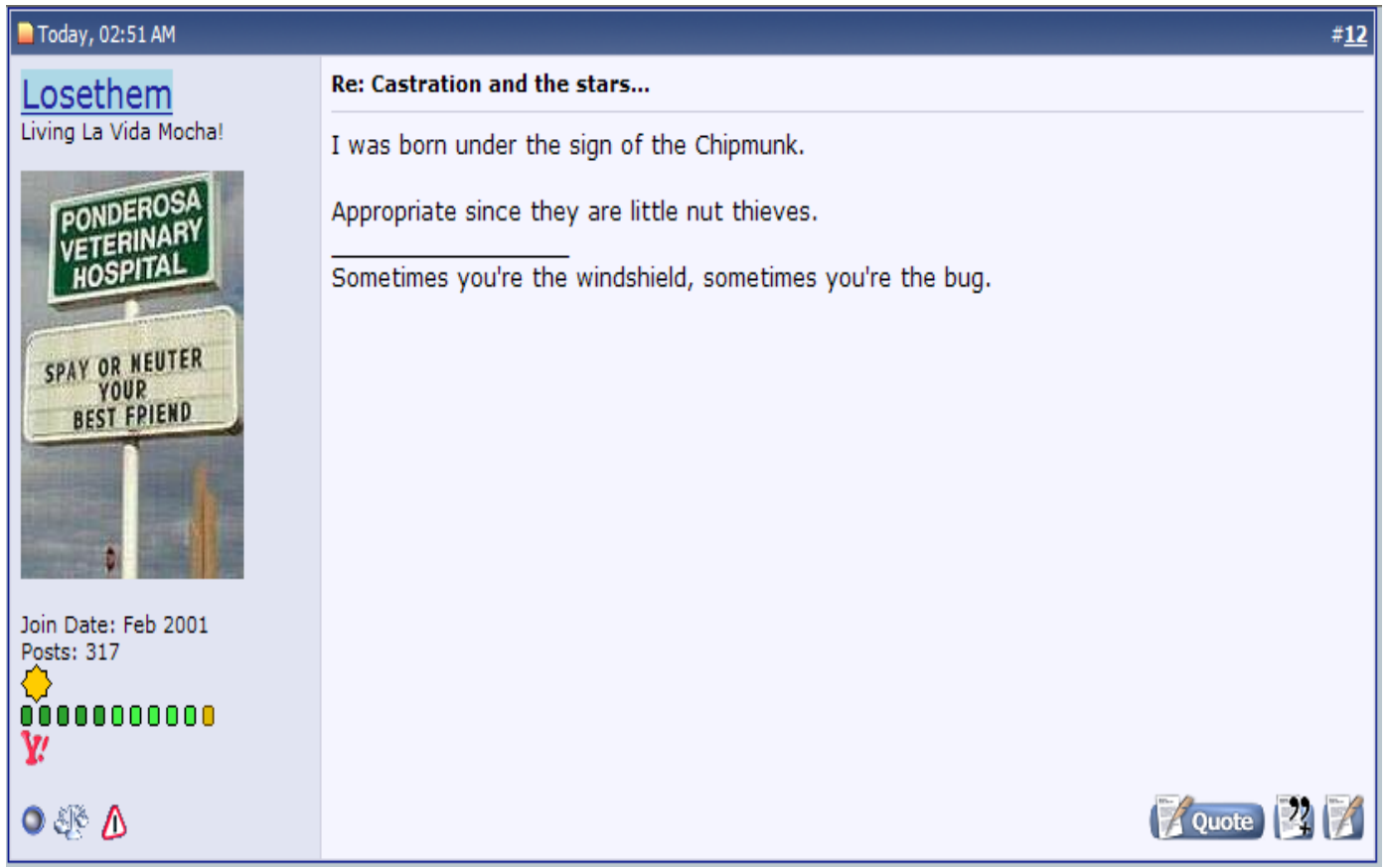

Figure E: Screen capture of Losethem's message 


\section{SARE, Vol. 54, Issue $1 \mid 2017$}

In connecting being a eunuch to astrology and the horoscope, Losethem claims to have been born under the sign of the Chipmunk, and jokingly writes, "Appropriate since they are little nut thieves" - 'nut' being a colloquial reference to his testicles. Thus, it could be read that Losethem steals his own 'nuts' from himself. This reproduction of the eunuch self in online interaction is not a conflicted representation. It is a playful and humorous reproduction with an implicitly reflexive awareness about it.

In his declaration of his birth and identity genders on his public profile (Figure F), Losethem, just like Bobbie, considers himself a 'genetic male'. However, unlike Bobbie, Losethem does not seem to reject sexuality, and instead actively aligns himself with a gay orientation. Although Losethem was castrated in 2005, he still sees himself as sexualised (and claims to have a male partner). Unlike normative definitions in which the eunuch is perceived to be impotent and devoid of desire and sex, the CyborgianTrans figure of Losethem actively brings desire and sex into the makeup of his eunuch self. Just as significantly, being a eunuch does not de-mark him from his outward (physical) masculine appearance, which he is perfectly happy to continue with as indicated by the assertion that he "will remain outwardly male". Thus, while Losethem may not have a fully functioning phallus, he does not discount his physical appearance as 'outwardly male'.

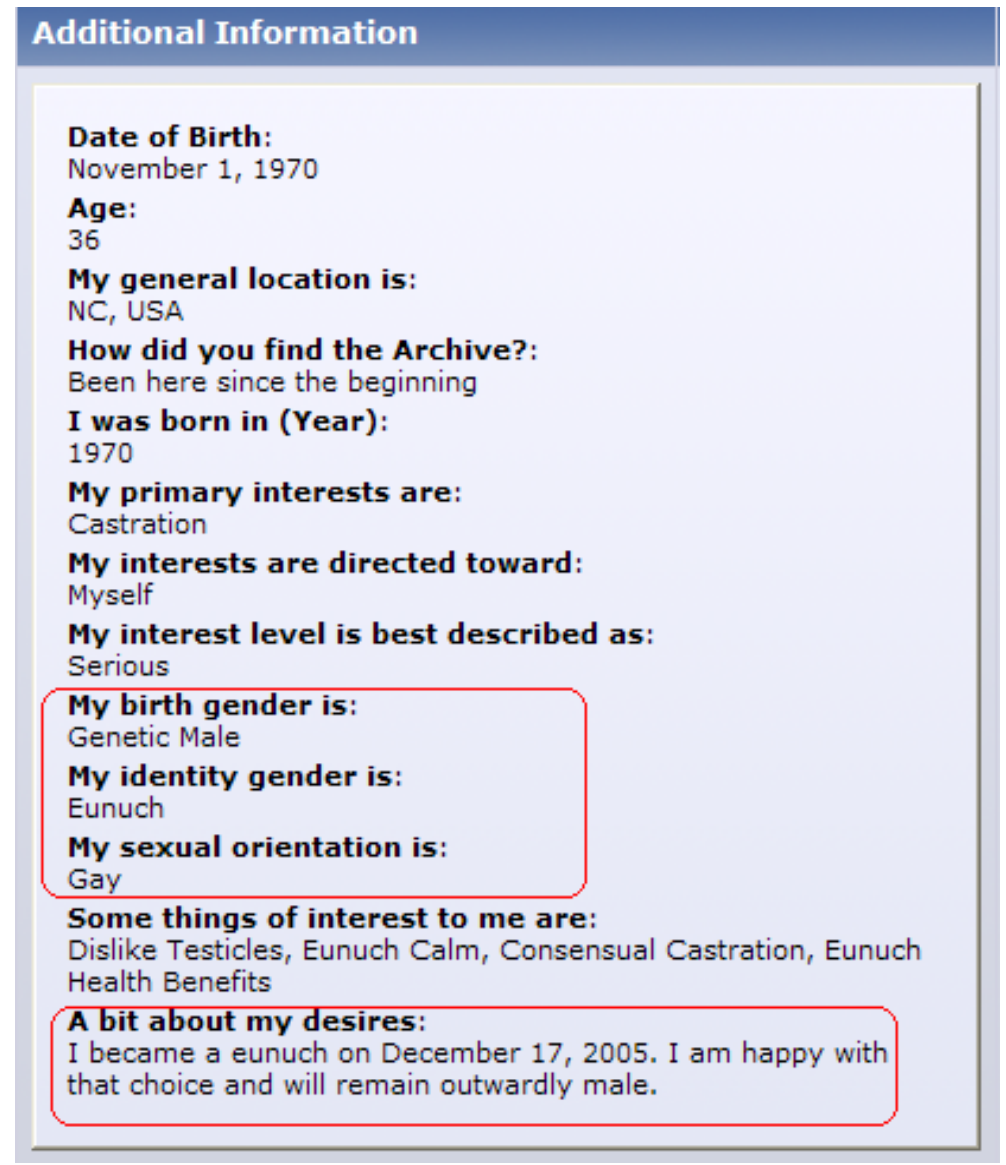

Figure F: Losethem's public profile

Losethem's CyborgianTrans subjectivity can be read as a complex rejection of normative heterosexual masculinity, which privileges the phallus, combined with a reworking of the boundaries of sexuality and desire to constitute a gender category called 'gay eunuch', (quite simply, a gay male without testicles) - a castrated male who is still sexualised. It is significant to note here that Losethem is not just a CyborgianTrans figuration in the virtual world, but also in the offline world, where he has employed the tools of technology that enabled 
him to surgically alter his physical appearance to create a hybrid self. Thus, the discursive construction and presentation of both a literal and figurative eunuch self by this particular CyborgianTrans figure has material effects in terms of his offline embodiment.

\section{joydivision_27}

In example 3, I explore another version of the eunuch that disrupts the fixed boundaries between male, female, gay, straight and eunuch; that of the 'gay male with a vagina'. joydivision_27's CyborgianTrans figure actively disrupts clear and clean gender categories through a reflexive self-awareness.

The name 'joy division' itself seems to be an intertextual reference to the influential English iconic punk rock band popular in the 1970s, which created new spaces and genres for rock music in the 1980s and beyond.

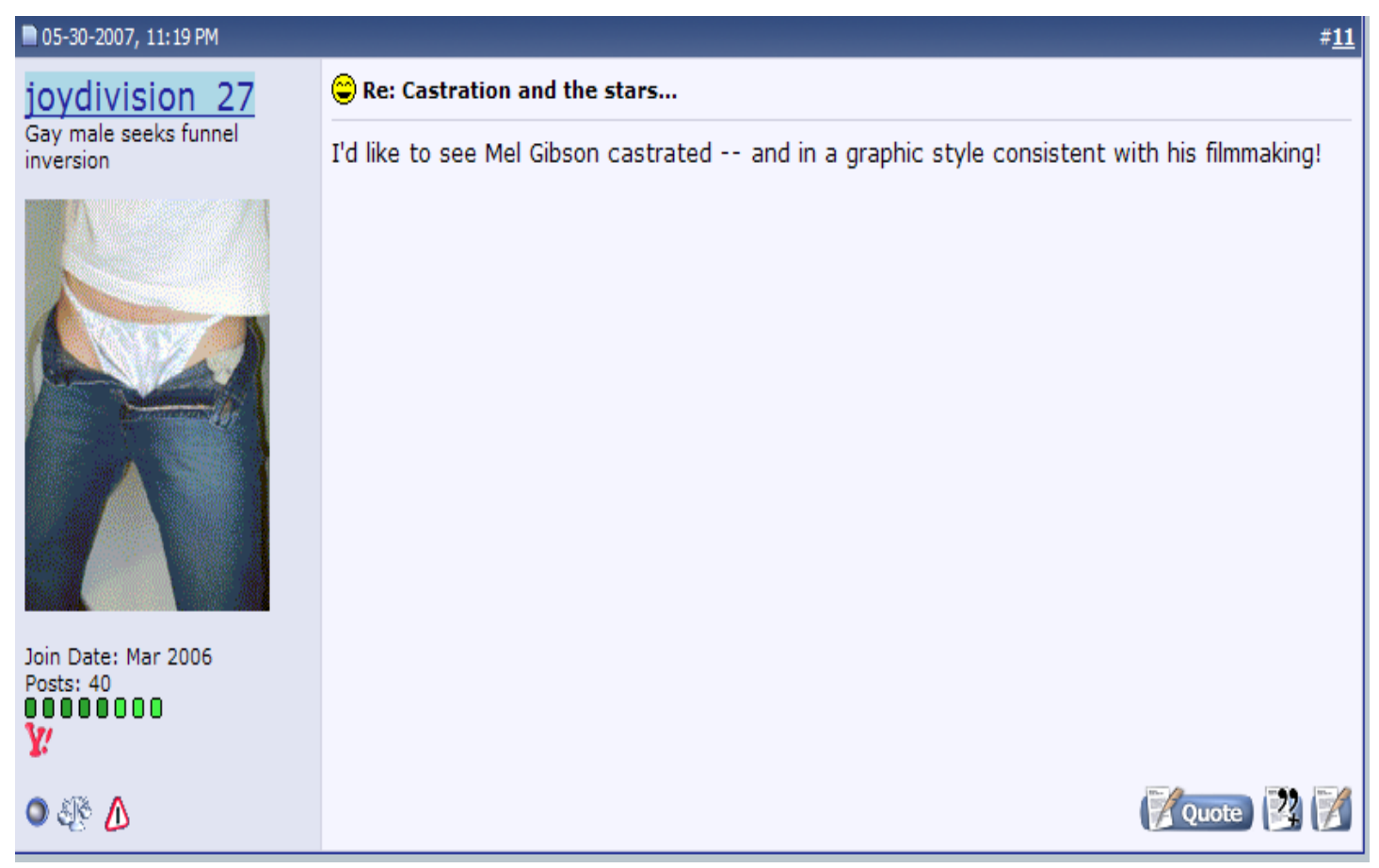

Figure G: Screen capture of joydivision_27's message

In this message, joydivision_27's avatar is of main interest. Unlike the previous two members, Bobbie and Losethem, joydivision_27's avatar is an actual photograph of the bottom half of a somewhat 'effeminate' and ambiguous body. With the zip of the jeans undone, the audience are positioned to see the genitalia covered by silvery white underwear that could be a woman's. Furthermore, the absence of overtly masculine genitalia is suggested in the image, and the viewers are positioned to presume that the underwear covers female genitalia. It is difficult to make out if the figure belongs to a male or female precisely because the image is meant to be ambiguous, and presumably, to leave the viewers doubtful. The caption above the image (below the name) "Gay male seeks funnel inversion" - makes the image even more ambiguous. The phrase 'funnel inversion' is the viewers' first clue to the alternative subjectivities that joydivision_27 is attempting to perform online - he not only wants to remove his masculine genitalia (like Losethem) but also to replace them with female genitalia. 


\section{SARE, Vol. 54, Issue $1 \mid 2017$}

Although joydivision_27 indicates his 'birth gender' as 'genetic male', it is not a categorisation that he rejects quite unambiguously. Rather, his indication that his 'identity gender' is 'male' while his sexual orientation is 'Gay male with a vag' (see Figure H), disrupts the normative boundaries of male/female and heterosexual/homosexual categorisations. Normative views of gender, sex and sexuality would attempt to locate joydivision_27 within clean closed off boxes of either male or female, and, as gay or straight (or even bisexual). However, the online self-reproduction of joydivision_27 is problematic because it is simultaneously none of these and yet all of these. The online persona of joydivision_27 indicates that he wants to convert his 'penis and testes' into a 'vagina', yet he wants to 'continue living as a gay man' (my emphasis).

While he wants to replace his male genitalia with a female one, he does not however, want to replace his male identity with a female one. It can be inferred that while he wants the female vagina, he does not want to change the rest of his outward appearance to being more feminine (i.e. he does not want feminine breasts, body shape or even to dress as a female), nor does he want to be identified socially as 'female'. Thus, joydivision_27's desire for female genitalia cannot be classified simply in terms of a sex-change operation.

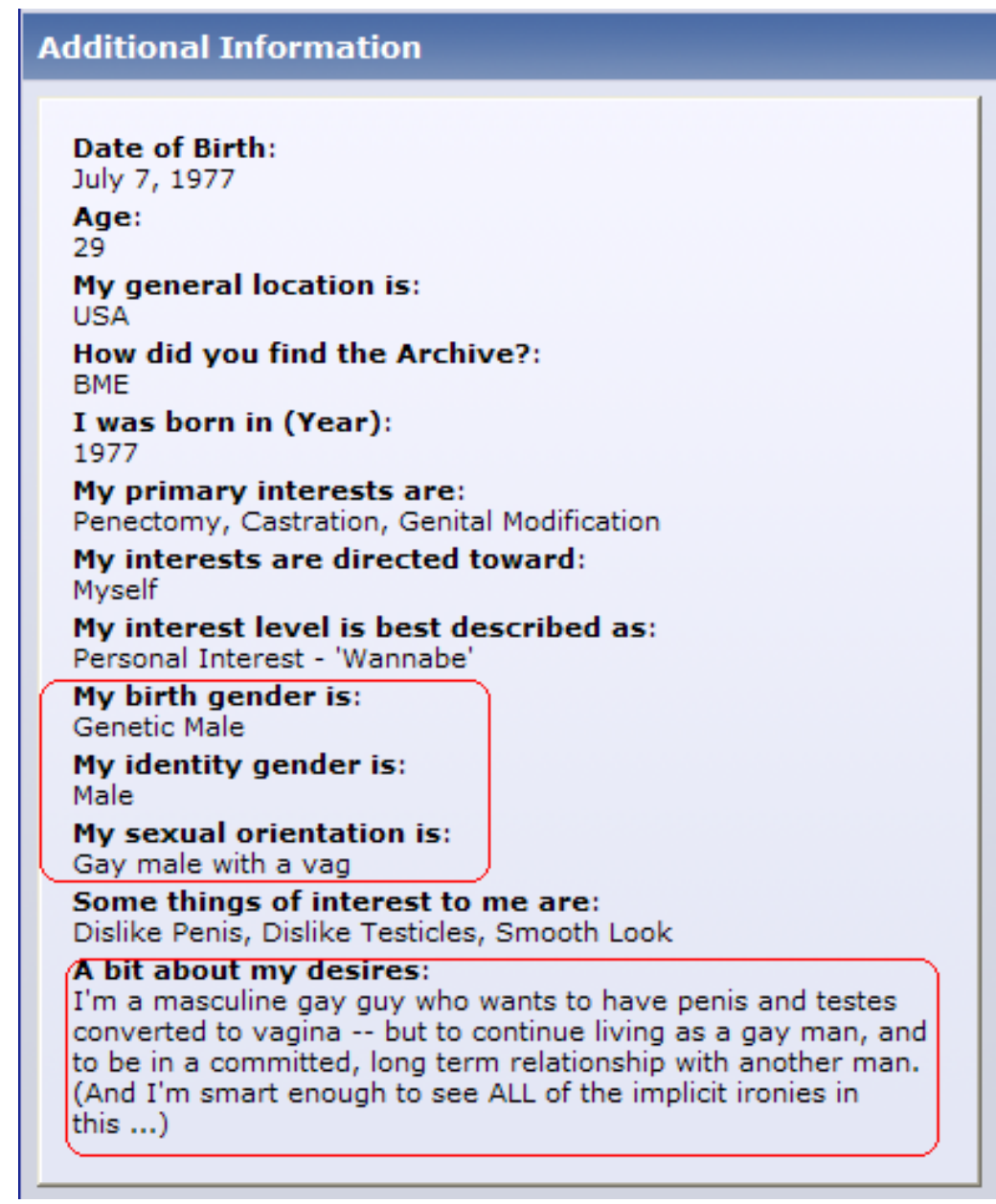

Figure H: joydivision_27's public profile

By asserting that he wishes to replace his male genitalia with female genitalia, yet continue to identify as a 'gay man', joydivision_27 disassociates all the normative links (and conflations) between sex-gender and sexgender-desire. Female genitalia indicate a female sex and gender in the normative performativity of gender. In joydivision_27's alternative performativity of gender, sex does not equate to gender. For this 


\section{SARE, Vol. 54, Issue 1 | 2017}

CyborgianTrans figure, possessing a vagina does not equate to the female sex, nor does it equate to the female gender. For joydivision_27, replacing his male organs with a female one cannot be seen in terms of a sex (and gender)-change. Physical markers of sex that in turn mark gender are not just disrupted, but thrown completely out of kilter. For the CyborgianTrans then, female genitalia do not have to indicate a 'female' gender - the possession of a vagina is reconfigured to indicate a male with homosexual desires, thus reinventing and reconfiguring the normative sex-gender system into an alternative definition for the term eunuch itself. In Butlerian terms, this is indeed a subversive act that seeks to use the normative binaries of sex and gender and subvert them completely.

Just as importantly, the CyborgianTrans is acutely aware of actively disrupting normative sex-gender boundaries. The reflexive awareness of joydivision_27 is indicated in his assertion that he is "smart enough to see ALL of the implicit ironies in this". In the physical offline world, joydivision_27 is considered a gay male due to his sex, gender and desire which is classified within normative categories. Since he has not had any kind of surgical reconstruction done to his body, the offline physical body of joydivision_27 will probably to all intents and purposes remain (for some time at least) within these normative classifications of sex, gender, and desire. In the offline, material world, joydivision_27 would probably not be classified as a eunuch in the literal sense. Yet, the online self-reproduction of joydivision_27 as a CyborgianTrans consciously constructs not just a figurative eunuch self but also rearticulates this figurative eunuch in alternative ways. Joydivision_27 reflexively uses the tools of writing (and visuals) to not only re-present his offline self, but to reinvent and reproduce it in alternative ways that break down the normative conflations of sex and gender, opening up possibilities of seeing sex, gender, and desire in different terms.

\section{Kangan}

Figure I illustrate the CyborgianTrans figure of Kangan, who voices another version of eunuch subjectivity:

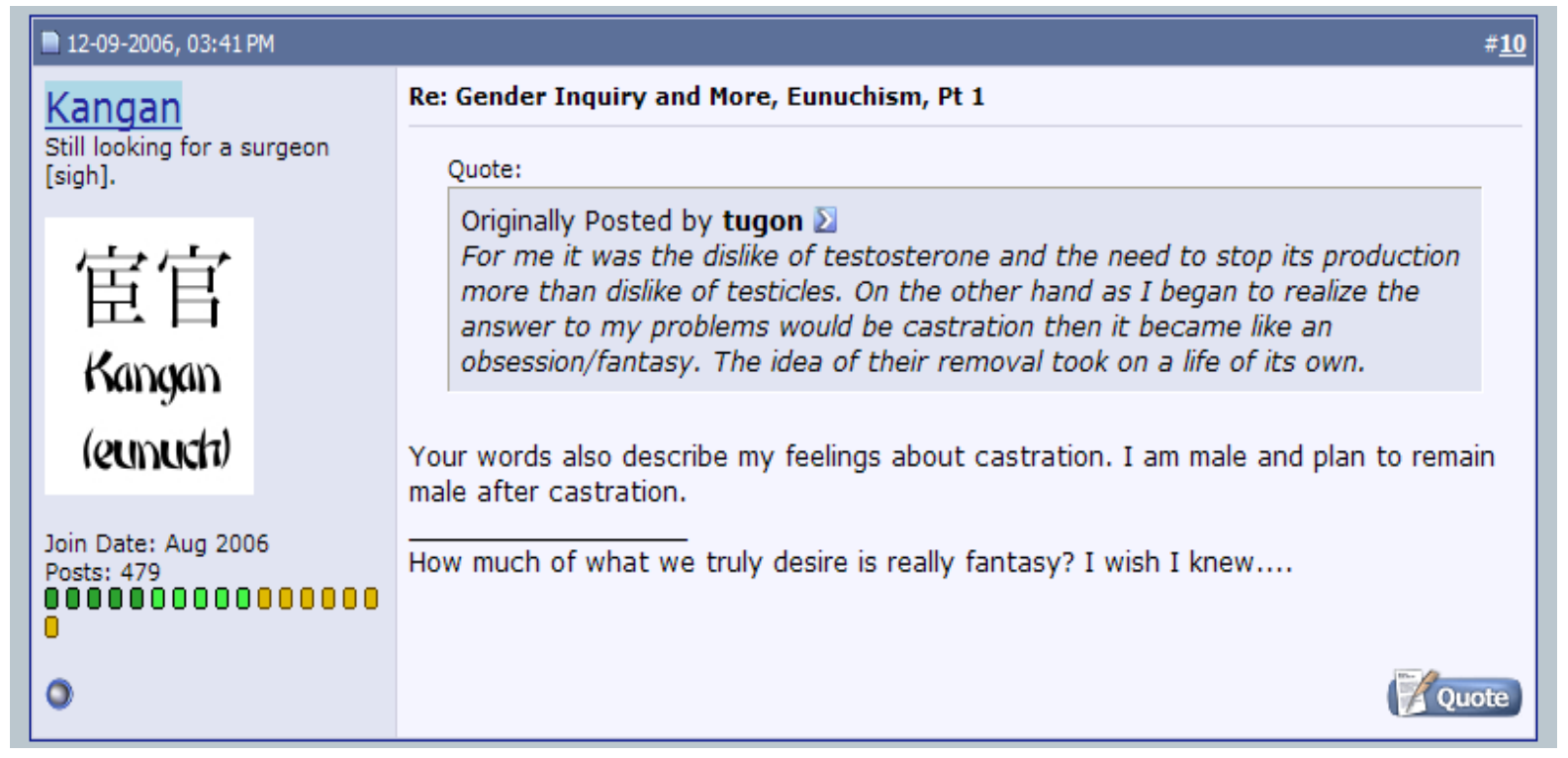

Figure I: Kangan's post

A close look at the nickname shows us that this user goes by the name Kangan, which is the Japanese word for a 'court eunuch'. The name Kangan and its English counterpart eunuch are reproduced in the avatar of the 


\section{SARE, Vol. 54, Issue 1 | 2017}

user in both Japanese script as well as English (note that the English script is written in the form of Japanese calligraphy). This avatar is a combination of image and text and actively reproduces the presence of the offline self in the online world of message boards. The statement plus textual indication of an emotion under the user-name Kangan, "still looking for a surgeon [sigh]" suggests that the material offline body of Kangan has not yet undergone castration. (As the public profile for Kangan states that he is from Southern Illinois in United States where castration is not legal unless for medical reasons [such as health or sex change operations], it can be assumed that Kangan is facing problems finding a surgeon who will perform the castration for him). Kangan's nickname and avatar are deliberate constructions, which can be seen as reflecting an ambiguous embodiment offline in terms of sex/gender/desire distinctions.

Also, significant here is the textual writing of Kangan. The declarative speech act, "I am male and plan to remain male after castration", is a curious one because 'being male' under conventional heterosexual norms is intertwined inextricably with the production of testosterone, and a fully functioning penis and scrotum. Castration would eradicate all these from Kangan's material body, yet he states that he will 'remain male' (presumably because he will still have a penis even if it is no longer fully functioning). It is significant to point out here that Kangan indicates in other posts that he is married and intends to continue sexual relations with his wife after the castration. Kangan then embodies a CyborgianTrans because he sits on the boundary that transgresses several boundaries - the boundary between organism and machine/technology, the boundary between the material and non-material, and, most importantly, the gender boundaries between 'male', 'notmale' and 'female'. Although physically, Kangan is not yet a eunuch (and may not ever be a eunuch unless he finds a surgeon who is willing to carry out the castration procedure), in the virtual space of the online message boards, Kangan has constructed an online self that is a eunuch. The CyborgianTrans figure of Kangan (through his online avatar and nickname) heralds a potentially revolutionary promise for the eunuch body to inhabit the in-between boundaries of gender - in the social imaginary space of the online message boards, his is a male body which is simultaneously not completely male, nor is it female.

\section{Multiple Subjectivities}

The analysis above works through the techniques of contrasting as well as exploring different perspectives. It explores what a eunuch is in normative terms and how the diverse and plural eunuch voices differ from normative expectations. In short, the multiple perspectives tell us what the eunuch is and is not. This shows that the 'original meanings ascribed to gender' (in this case male and eunuch) and their 'subsequent gender experience' are not always similar. In fact, they do not reveal simple dichotomies of sex/gender/desire either but rather complex and differing versions of 'eunuch', throwing into question the very definition of eunuch itself. The four voices discussed here present multiple ways of being a eunuch and a male, ways which at the same time also mark their resistance to normative interpretations of both those terms.

The four examples here show that while the very figure of the eunuch disrupts the normative categories of sex and gender, there is also no such thing as a coherent eunuch self. The eunuch self is normatively identified via self-evident bodily criteria, i.e. the absence of certain sex organs. The bodily criteria of the eunuch (or any biological body such as female or male) are ascribed with particular social meanings, which then bring about a specific and narrow social construction of the eunuch. However, the varying ways in which all four members define the physical and non-physical figure of the 'eunuch' and represent it in the online world, indicate that the figure of the 'eunuch' can be seen in diverse ways which, in turn, disrupt the sex- 


\section{SARE, Vol. 54, Issue $1 \mid 2017$}

gender system itself. The non-physical self-reproductions of these eunuchs illustrate the postmodern view that sex and gender identities should be seen in fragmented and diverse, instead of coherent and stable, terms.

The general meaning ascribed to the word 'eunuch' gives way to the more specific and particular experiences articulated by the posters. For the CyborgianTrans figures, in terms of subjectivities, the specific is more significant than the general. These four different posters offer four (and possibly more) different versions of what it means to be a 'eunuch'. Taken together, what we have is a montage or patchwork of images that enables partial and multiple representations of the gender category of 'eunuch'. The voices of these CyborgianTrans posters demonstrate that the gender category of 'eunuch' is not a foreclosed category even if normative gender performativity seeks to fix it as stable and given. 'Eunuch' is a discursive construction with very material effects, where the discursive production of meaning making is embodied in the material body. It is through the voices of these four posters that the ambiguities and multiple facets of the eunuch self is created and constituted, de-stabilising the purported 'reality' of 'eunuch' as a gender/sex category.

Indeed, the multiplicities of the CyborgianTrans figure in the online 'ideal' eunuch self-do disrupt normative perceptions of gender and sexuality. Significantly also, it must be noted that while the interface with information technology and computer mediated communication can be perceived as somewhat liberating, this paper is actually more focused upon the ways in which this interface with technology allows individuals to rearticulate the notion of the eunuch in ways that can potentially destabilise the very term 'eunuch' itself.

The dichotomy between the ideal body/self and the actual body/self is reconstituted in the online eunuch. The offline self is bounded by the body as well as many socio-cultural, religious, legal medical and financial constrictions, which may not allow the individual to arrive at or achieve the desired 'ideal' self which can be expressed in the online world. I argue that this online reconstitution and rearticulation of gender and sexual identity is significant because it allows the individual to use an imaginary resource to transcend the limitations and constraints of the material world and to consciously construct a fluid and non-rigid gender/sexual identity within a social imaginary that throws into flux the very definition of the 'eunuch'. This destabilisation opens up the possibility for multiple and complex definitions of the term itself, which in turn, open up possibilities for reshaping gender and sexual categories and identities.

\section{WORKS CITED}

\section{Braidotti, Rosi. Nomadic Subjects: Embodiment and Sexual Difference in Contemporary Feminist Theory.} Columbia UP, 1994.

Butler, Judith. Gender Trouble: Feminism and the Subversion of Identity. Routledge, 1999.

Foucault, Michel. The History of Sexuality. Pantheon Books, 1978.

Gunkel, David. “The real problem: avatars, metaphysics and online social interaction”. New Media \& Society, vol.12, no. 1, 2010, pp:127-141.

Haraway, Donna J. Simians, Cyborgs and Women: The Reinvention of Nature. Routledge, 1991

Roberts, L.F., Brett, M.A., Johnson, T.W., and Wassersug, R.J. “A passion for castration: characterizing men who are fascinated with castration, but have not been castrated". Journal of Sexual

Medicine, vol. 5, no.7, 2008, pp:1669-1680. 
Scott-Dixon, Krista. (Ed). Trans/Forming Feminisms: Trans-Feminist Voices Speak Out. Sumach Press, 2006.

Turkle, Sherry. The Second Self: Computers and the Human Spirit. MIT Press, 2005.

Vale, K., Johnson, T.W., Jansen, M.S., Lawson, B.K., Lieberman, T.,Willette, K.H., \& Wassersug, R.J. “The development of standards of care for individuals with a male-to-eunuch gender identity disorder". International Journal of Transgenderism, vol.12, no. 1, 2010, pp:40-51.

Vale, K., Siemens, I., Johnson, T.W., and Wassersug, R.J. "Religiosity, childhood abuse, and other risk factors correlated with voluntary genital ablation". Canadian Journal of Behavioural Science, vol.45, no. 3, 2013, pp:230-237.

Yuval-Davies, Nira. "Women, ethnicity and empowerment." Feminism and Psychology, vol.4, no. 1, 1994, pp:179-197. 